Open Access

\title{
The haemodynamic effects of crystalloid and colloid volume resuscitation on primary, derived and efficiency variables in post-CABG patients
}

\author{
S. Sondergaard ${ }^{1 *}$ (D, J. S. Larsson ${ }^{2}$ and P. W. Möller ${ }^{3}$
}

* Correspondence: sondergaard. soren@gmail.com

${ }^{1}$ Centre of Elective Surgery, Department of Anaesthesia and Intensive Care, Silkeborg Regional Hospital, Silkeborg, Denmark Full list of author information is available at the end of the article

\begin{abstract}
Background: Recent studies in haemodynamic management have focused on fluid management and assessed its effects in terms of increase in cardiac output based on fluid challenges or variations in pulse pressure caused by cyclical positive pressure ventilation. The theoretical scope may be characterised as Starling-oriented. This approach ignores the actual events of right-sided excitation and left-sided response which is consistently described in a Guyton-oriented model of the cardiovascular system.

Aim: Based on data from a previous study, we aim to elucidate the primary response to crystalloid and colloid fluids in terms of cardiac output, mean blood pressure and right atrial pressure as well as derived and efficiency variables defined in terms of Guyton venous return physiology.

Method: Re-analyses of previously published data.

Results: Cardiac output invariably increased on infusion of crystalloid and colloid solutions, whereas static and dynamic efficiency measures declined in spite of increasing pressure gradient for venous return.
\end{abstract}

Discussion: We argue that primary as well as derived and efficiency measures should be reported and discussed when haemodynamic studies are reported involving fluid administrations.

Keywords: Haemodynamics, Methods, Physiology, Utilisation, Models, Cardiovascular, Fluid therapy

\section{Background}

Assessment of cardiovascular regulation in the perioperative period is a highly debated topic in anaesthesia concerning goals, evaluation and choice of therapy. The ultimate purpose of regulation is to ensure that oxygen delivery $\left(\mathrm{DO}_{2}\right)$ does not rate-limit the oxygen consumption $\left(\mathrm{VO}_{2}\right)$ by maintaining a cardiac output $(\mathrm{CO})$ at prevailing haemoglobin $(\mathrm{Hb})$ and oxygen saturation $\left(\mathrm{S}_{\mathrm{a}} \mathrm{O}_{2}\right)$. The attainment of a targeted $\mathrm{CO}$ may be accomplished using a number of strategies suggested by established algorithms based on an implicit Starling cardiocentric model. In this, the qualitative description of the cardiac function curve has three determinants: preload, afterload and contractility. Volume resuscitation is a means of increasing preload, 'moving' the volume responsive patient up the function curve

(c) The Author(s). 2019 Open Access This article is distributed under the terms of the Creative Commons Attribution 4.0 International License (http://creativecommons.org/licenses/by/4.0/), which permits unrestricted use, distribution, and reproduction in any medium, provided you give appropriate credit to the original author(s) and the source, provide a link to the Creative Commons license, and indicate if changes were made. 
in terms of preload vs CO. We observe the increase in CO with a cut-off at $10-15 \%$ (dictated by minimum discernible difference of $\mathrm{CO}$ monitor) in response to a volume increment of 250-500 mL of fluid. It is, however, often unspecified which type of fluid and whether the volume should be fixed, related to body size or adapted to the vascular compliance of the patient and which infusion rate should be used. Inotropy is another option increasing $\mathrm{CO}$, and guidelines usually refer the clinician to the use of inotropic therapy when the preloading option does not confer a CO increase $>10 \%$. In the Starling model, there is no option for quantifying the 'cost' of volume resuscitation, o: how efficiently added volume results in an increase in cardiac power ((MAP - CVP) $\times \mathrm{CO})$, nor numerically characterise heart efficiency and changes therein.

Looking at cardiovascular regulation from a Guytonian, histocentric perspective (i.e. the oxygen demand of the tissues plays the major role in regulating venous return and consequently the cardiac output), the determinants of $\mathrm{CO}$ are volume (expressed as mean systemic filling pressure), vascular resistance and heart efficiency. These are well-defined and quantitative in the Parkin and Leaning haemodynamic model. When integrated into and presented bedside in a clinical decision support system (CDSS), they provide the option of quantifying the effects of and guide therapy.

This study used imported data from Skytte Larsson [1] and aims to describe similarities and differences in the course of crystalloid and colloid resuscitation. We analysed primary (MAP, CO, RAP), derived and efficiency variables to compare fluid resuscitation in coronary artery bypass patients seen from a Starling and Guytonian perspective.

\section{Patients and measurements}

Thirty stable, post-operative CABG patients were allocated in random order after informed, signed consent to receive Ringer's Acetate $20 \mathrm{~mL} / \mathrm{kg}$ or Voluven 130/0.4 (Fresenius $\mathrm{Kabi}$ ) $10 \mathrm{~mL} / \mathrm{kg}$ over a period of 20-30 min to allow for stress relaxation. In a previous study, these volumes generated identical relative increases in $\mathrm{CO}$ and were regarded as equivalent in this sense. Prior to infusion, duplicate control baseline haemodynamic measurements were performed consisting of transcardiac thermodilution cardiac output (TDCO) in triplicate within 10\%, mean arterial and central venous pressure (MAP, CVP) with pressure sensors aligned to phlebostatic axis at midaxillary level. MAP, CVP and CO are the primary variables. Arterial and venous blood gases were analysed. Post-infusion at 20, 40 and $60 \mathrm{~min}\left(t^{20}, t^{40}, t^{60}\right)$ measurements were repeated. Patients were ventilated in volume-controlled mode with a PEEP of $5 \mathrm{~cm} \mathrm{H}_{2} \mathrm{O}$ at a respiratory rate of $12-16 \mathrm{~min}^{-1}$ using a tidal volume $6-8 \mathrm{~mL} / \mathrm{kg}$ to maintain normocarbia. Sedation was provided using propofol and morphine. Patient demographics are shown in Table 1. Haemodynamic and gas analysis data are available on request.

\section{Calculations}

\section{Fluid retention}

The retention of fluid (FR) is a complex function of fluid composition, osmotic pressure, intravascular pressure and disease state. The resultant 'percentage fluid retained of transfused volume' was estimated according to: 
$\Delta \mathrm{BV}=\mathrm{BV}\left(\mathrm{Hb} / \mathrm{Hb}_{\mathrm{t}}\right)-\mathrm{BV} ; \mathrm{Hb}$, haemoglobin; $\mathrm{BV}$, blood volume.

The amount of fluid retained in the blood is given by

FR $(\%)=100 \times \Delta B V /$ infused volume.

BV was calculated according to the Nadler equation [2].

Men: $\mathrm{BV}=\left(0.3669 \times \mathrm{H}^{3}\right)+(0.03219 \times \mathrm{W})+0.6041$.

Women: $\mathrm{BV}=\left(0.3561 \times \mathrm{H}^{3}\right)+(0.03308 \times \mathrm{W})+0.1833$.

$\mathrm{H}$, height, $\mathrm{m}$; W, weight, kg.

\section{Derivation of Guytonian model variables}

Central to the Guytonian model is the mean systemic filling pressure, $P_{\mathrm{ms}}$, originally introduced by Weber [3] and half a century later revived by Starling [4]. Guyton formalised the study of $P_{\mathrm{ms}}$ in a monumental series of investigations [5-9] summarised in his Cardiac Output and its Regulation. [10] Whereas Guyton defined $P_{\mathrm{ms}}$ as the equilibrated arteriovenous pressure at zero flow (fibrillation), a number of alternative methods have been suggested to elicit $P_{\mathrm{ms}}$ in the intact circulation. Some of these are interventional: the cardiovascular system is excited and its response is registered [11-17]. For validity, this carries the implication of the stability of all other variables entering the function of the cardiovascular system during the excitation. It is limited to sedated patients in fully controlled ventilation. $P_{\mathrm{ms}}$ has a normal value of $7-12 \mathrm{mmHg}[9,18]$.

The estimation of $P_{\mathrm{ms}}$ has been approached from a purely computational angle by Parkin and Leaning. $[19,20]$ Based on a simple circulatory model, the following equation is offered as an analogue to $P_{\mathrm{ms}}: P_{\mathrm{msa}}=0.96 \times \mathrm{CVP}+0.04 \times \mathrm{MAP}+c \times \mathrm{CO}, c$ is based on anthropometric data and attains values of 0.4-1.2. A normal value of $P_{\text {msa }}$ is $7 \mathrm{mmHg}$ as seen in a patient in whom $\mathrm{CVP}=0, \mathrm{MAP}=100, \mathrm{CO}=6$ and $c=0.5 . P_{\mathrm{msa}}=$ $0.96 \times 0+0.04 \times 100+0.5 \times 6=7$. [18]

A fluid bolus invariably raises the mean systemic filling pressure $\left(P_{\text {msa }}\right)$ ceteris paribus. The outcome of fluid resuscitation is illustrated in Fig. 1 in the combination of Starling's cardiac function curve and Guyton's venous return curve. Depending on the position of the intercept of the venous return and the cardiac function curve, CVP and $\mathrm{CO}$ change in distinct patterns. If the venous return curves associated with $\Delta P_{\text {msa }}$ intercept with the ascending limb of the function curve, CVP rises minimally, while CO responds to the increase in the potential energy added to the venous capacitance. In contrast, if the venous return curves associated with $\Delta P_{\text {msa }}$ intercept the function curve in the flat part, the $\mathrm{CO}$ changes minimally and CVP increases substantially.

In addition to $P_{\mathrm{msa}}$, the driving pressure for venous return $\left(\mathrm{VRdP}=P_{\mathrm{msa}}-\mathrm{CVP}\right)$ and power $((\mathrm{MAP}-\mathrm{CVP}) \times \mathrm{CO})$ belong to derived variables. The assembly further allows for the definition of three efficiency variables, $E_{\mathrm{h}}, E_{\mathrm{vol}}$ and $E_{\text {power }}$. $E_{\mathrm{h}}$, heart efficiency, expresses how well the heart handles the VRdP in terms of $P_{\text {msa }}$ and CVP. Whereas $E_{\mathrm{h}}$ is a static variable, $E_{\mathrm{vol}}$ conveys a dynamic variable embodying the efficiency of added volume in terms of increase in VRdP related to increase in $P_{\text {msa }} . P_{\text {power }}$ power efficiency, dynamically describes the change in cardiac power in relation to the change in $P_{\mathrm{msa}}$. Notably, the variables are continuous in the interval $[0 ; 1]$ in contrast to the prevalent binary variable 'volume responsiveness': responder/non-responder. See Appendix for 


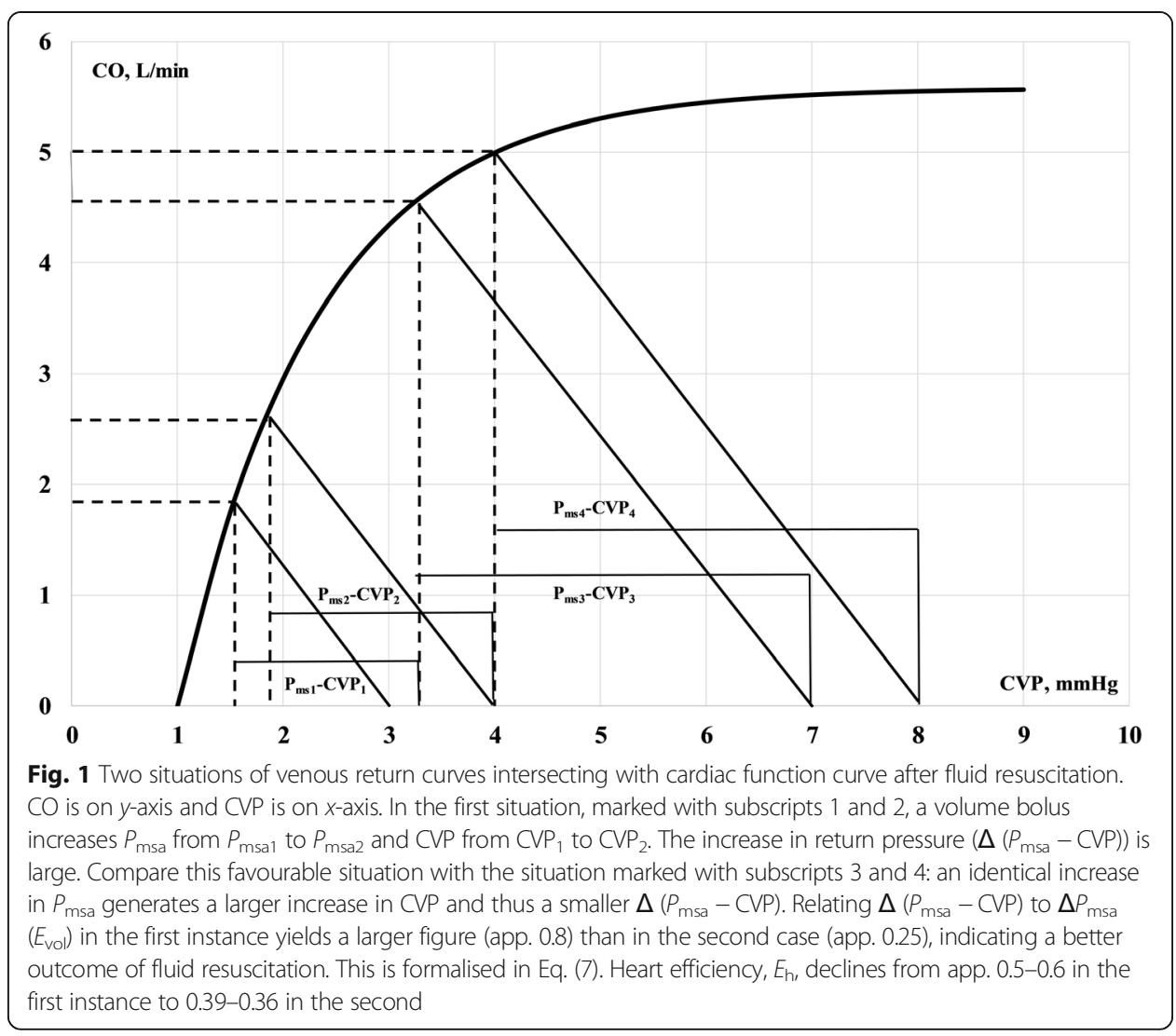

derivations of heart $\left(E_{\mathrm{h}}\right)$, volume $\left(E_{\mathrm{vol}}\right)$ and power efficiency $\left(E_{\text {power }}\right)$. The relationship between the evolution of CVP, $E_{\mathrm{vol}}, E_{\text {power }}$ and the Starling cardiac function curve is illustrated in Fig. 2.

\section{Statistical analysis}

Primary, derived and efficiency variables were normally distributed and are characterised by mean and standard deviation; differences between time points and types of fluids were analysed by ANOVA with multiple comparisons and multiplicity adjusted $p$ values, Tukey test, confidence intervals and significance. Analyses were performed using GraphPad Prism versions 6.05 and 8.01 (La Jolla, CA 92037, USA).

Table 1 Demographics, mean and standard deviation (SD) of patients

\begin{tabular}{lll}
\hline & \multicolumn{2}{c}{ Patients receiving } \\
\cline { 2 - 3 } & Crystalloid & Colloid \\
\hline Gender (F/M) & $3 / 12$ & $1 / 14$ \\
Age, years & $68 \pm 12$ & $66 \pm 10$ \\
Length, $\mathrm{cm}$ & $174 \pm 8.5$ & $176 \pm 6.4$ \\
Weight, $\mathrm{kg}$ & $78.7 \pm 11$ & $78 \pm 8.6$ \\
BSA, $\mathrm{m}^{2}$ & $1.94 \pm 0.18$ & $1.94 \pm 0.13$ \\
\hline
\end{tabular}




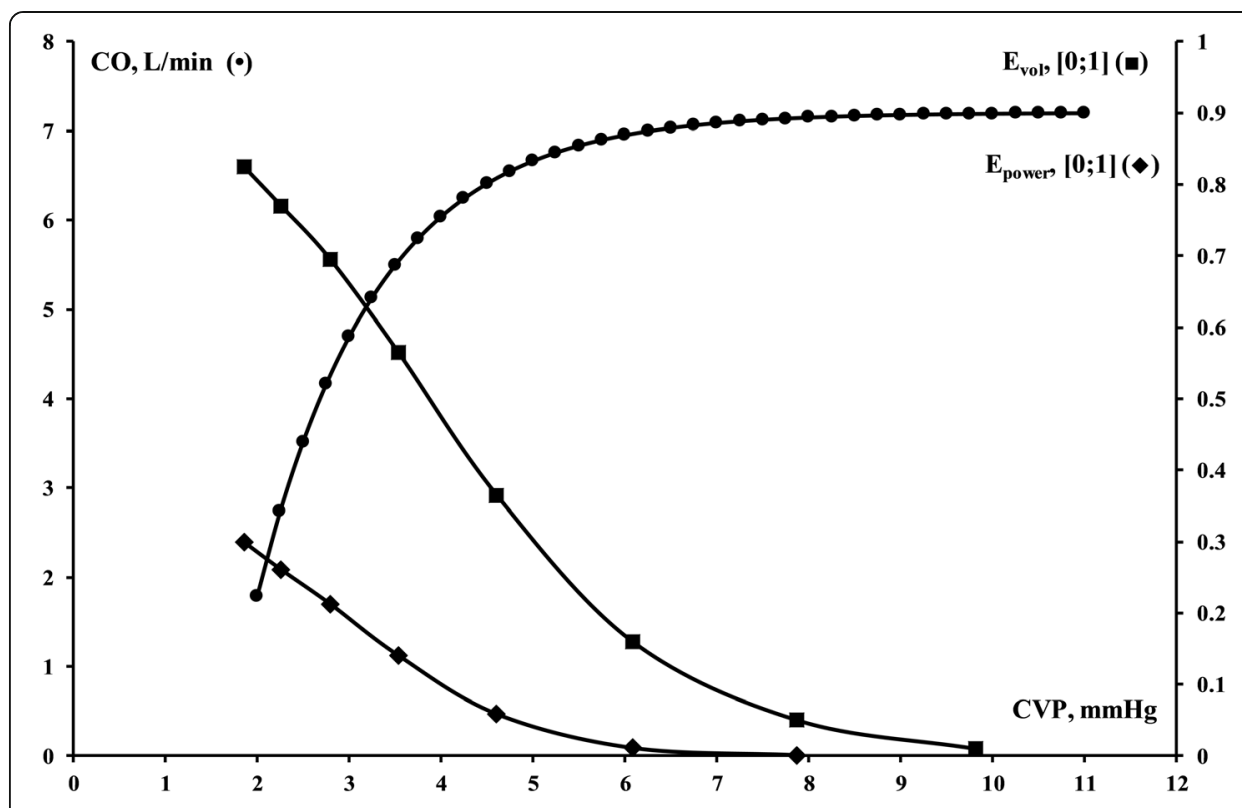

Fig. $\mathbf{2}$ Concordant cardiac function curve (filled circle), volume efficiency (filled square) and power efficiency (filled diamond) as $P_{\text {msa }}$ is increased stepwise by $2 \mathrm{mmHg}$. Power efficiency has been scaled by a factor 10 for visibility

\section{Results}

Patients

\section{Fluid retention}

Coefficients of variation in $\mathrm{Hb}$ were 13.7 and $13.6 \%$ in the crystalloid and 12.8 and $13.0 \%$ in the colloid baseline measurements. Percentages FR for colloid and crystalloid resuscitation are shown in Fig. 3. The differences between crystalloid FR at $t^{20}$ to $t^{40}$ and $t^{20}$ to $t^{60}$ were significant. The drop in colloid FR from $t^{40}$ to $t^{60}$ was significant. The

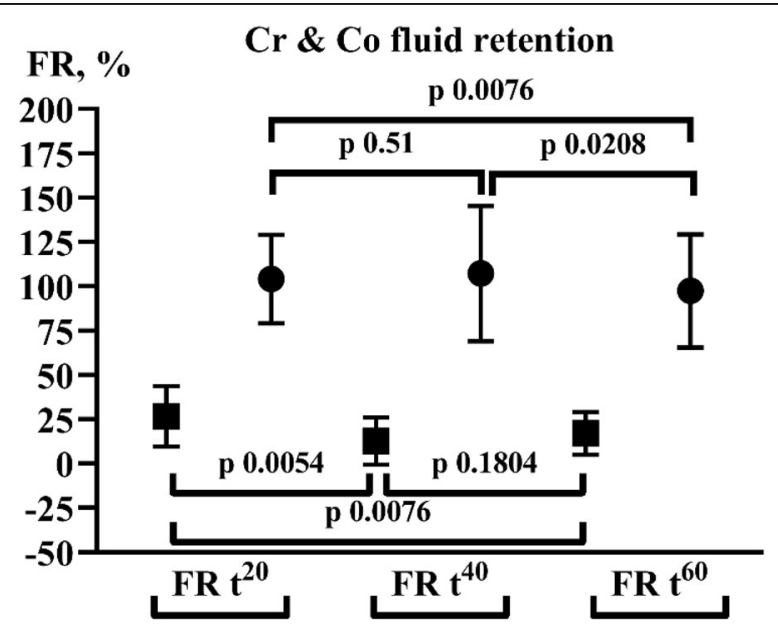

Fig. 3 Fluid retention after one, two and three 20 min periods in the crystalloid (Cr, full square) and colloid (Co, full circle) group 
differences between the fluid types were significant at all time points $(p=<0.0001)$. So, in short, crystalloid fluids leave the circulation, colloid stay.

\section{Primary variables}

The primary variables MAP, CVP and CO increased significantly after colloid resuscitation. In the crystalloid group, this only happened in CO. This was followed by a significant decrease in $\mathrm{CO}$ in the crystalloid series. The average COs in crystalloid and colloid groups at baseline were 4.82 and $5.11 \mathrm{~L} / \mathrm{min}$. At $t^{20}$, the mean COs were 5.58 and $6.30 \mathrm{~L} / \mathrm{min}$. Neither at baseline nor at $t^{20}, t^{40}$ and $t^{60}$ were differences between crystalloid and colloid CO significantly different. The maximum $\triangle \mathrm{CO}$ were 15.6 and $22 \%$ in the crystalloid and colloid groups. There were no other significant differences in MAP, RAP or CO at identical time points between crystalloid and colloid series, see Fig. 4.

\section{Derived variables}

The derived variables $P_{\mathrm{msa}}$, and $\left(P_{\mathrm{msa}}-\mathrm{CVP}\right)$ and power increased significantly. Power increased significantly in both series from control measurement to $t^{20}$ and $t^{40}$ in the crystalloid series after which power decreased. In the colloid series, power increases stayed significant for the duration of the experiment, see Fig. 5.

\section{Efficiency measures}

$E_{\mathrm{h}}$ as a static measure decreased significantly in the colloid group, but stayed constant in the crystalloid series. $E_{\mathrm{vol}}$, a dynamic measure, repeats the pattern of FR with significantly larger variance in crystalloid vs colloid group. $E_{\mathrm{vol}}$ did not demonstrate significant differences between time points in each series separately, nor differences between fluid types at identical time points. Insignificant declining efficiency is noted in crystalloid group, see Fig. 6.

Results of compliance calculations are depicted in Figure 7.

\section{Discussion}

The haemodynamic data originate from a study of the effect of resuscitation on renal perfusion and oxygenation. We aimed to illustrate the impact on primary, derived cardiovascular variables and efficiency measures. The purpose of the primary study was not to explore macrohaemodynamics by exciting the cardiovascular system. Our findings are co-incidental and not the result of any modification of goal-directed therapy (GDT). We will, however, discuss the results in the light of GDT as data collection is meticulous and detailed.

The analysis of cardiovascular effects of a crystalloid or colloid bolus in post-CABG patients demonstrated effects in primary variables (MAP, CO, CVP), derived variables $\left(C, P_{\mathrm{msa}},\left(P_{\mathrm{msa}}-\mathrm{CVP}\right)\right.$, power $)$ and the efficiency variables $\left(E_{\mathrm{h}}, E_{\mathrm{vol}}, E_{\mathrm{power}}\right)$. The primary variables increased significantly from baseline through $t^{20}, t^{40}$ to $t^{60}$ in the colloid series whereas only $\mathrm{CO}$ differed significantly through the crystalloid series-as $\mathrm{CO}$ deteriorated. The increase in $\mathrm{CO}$ is ascribed to the significant increase in $P_{\mathrm{msa}}$ and $\mathrm{VRdP}=$ $\left(P_{\mathrm{msa}}-\mathrm{CVP}\right)$ in the colloid group.

Important differences were seen in fluid retention; these were reflected in the significant differences in compliance between the crystalloid and the colloid group. Notably, the 


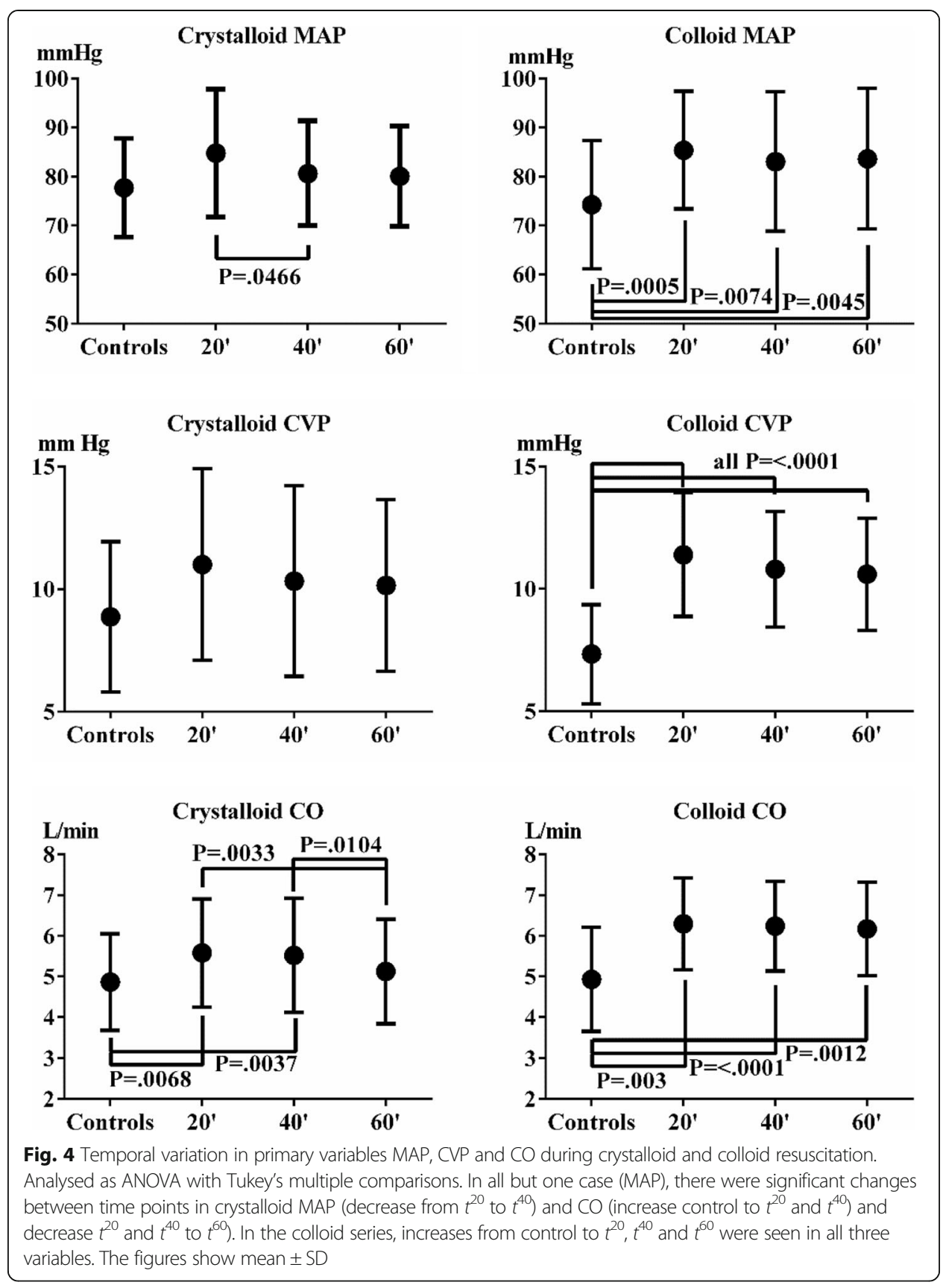

crystalloid shows lower fluid retention and higher compliance. This, however, is understandable as the $P_{\mathrm{msa}}$ increases less while less fluid is retained. The calculation of FR is hampered by the low precision of determination of haemoglobin. This, however, affects crystalloid and colloid series in equal measure. The study used haemoglobin-derived FR in order to avoid the influence of changes in tonicity on mean corpuscular volume, MCV and haematocrit (Hct). An experiment with identical (incidentally) amounts of fluid changed plasma colloid oncotic pressure by $8.3 \%$ in voluven group and by $-26.2 \%$ in the crystalloid group. [20]. In effect, this should increase mean corpuscular volume, MCV, and Hct in crystalloid while decreasing $\mathrm{MCV}$ and Hct relatively in colloid resuscitation. Calculated compliance, normally $1-2 \mathrm{~mL} / \mathrm{kg} / \mathrm{mmHg}$, therefore is a crude measure but concordant 


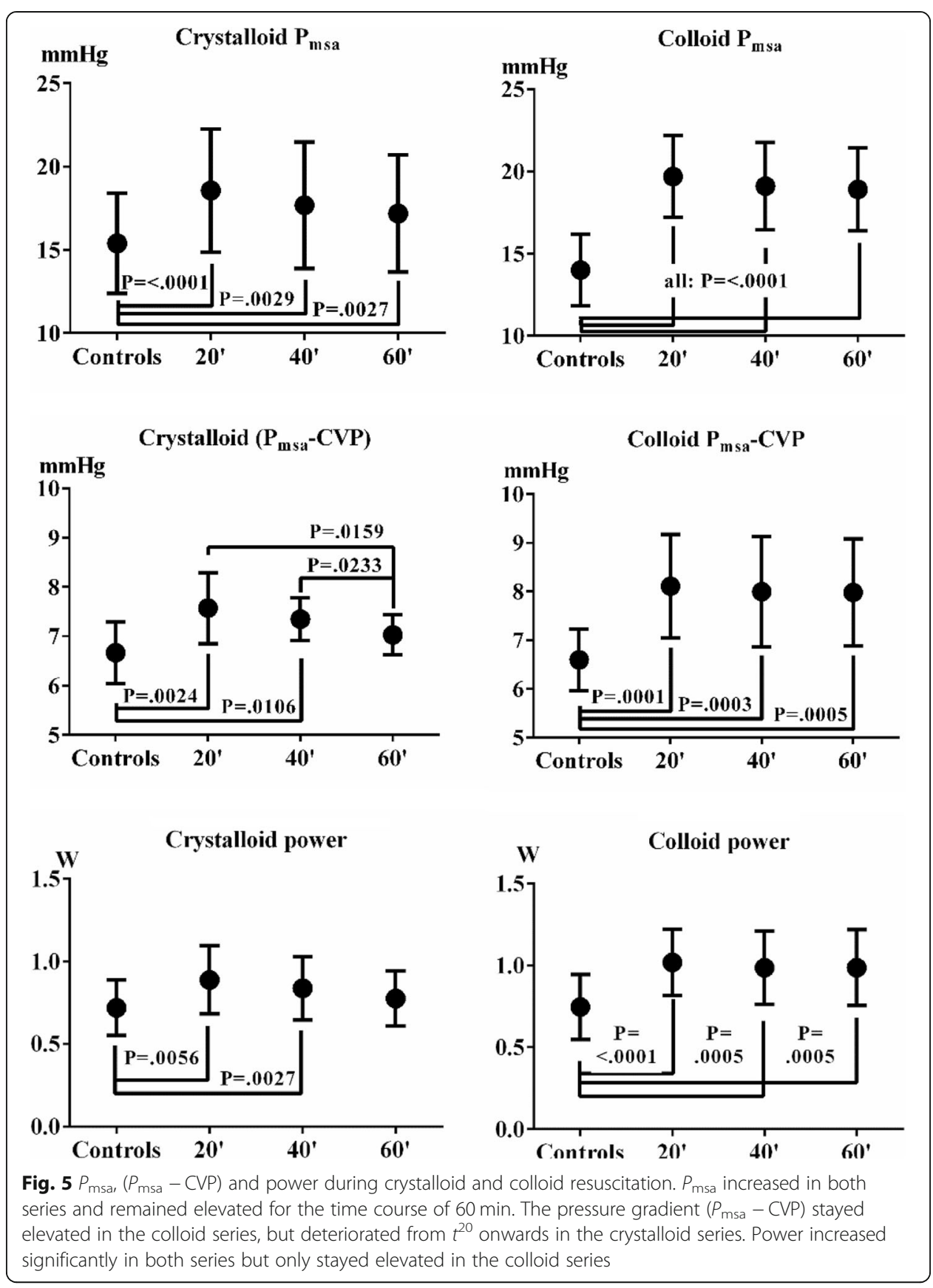

with previous results. [21] The low FR of crystalloid further means that the extravascular load of fluid may reach detrimental proportions in terms of tissue oedema resulting in reduced kidney, pulmonary, intestinal and hepatic function in addition to the immediate effect of certain crystalloids to degrade the glycocalyx (an effect they share with colloids!) and further promote extravasation. [22]

While the immediate effects on $\mathrm{CO}$ and MAP are the primary goals of fluid resuscitation, the scrutiny of the efficiency measures may answer the question whether fluid or other interventions will provide the haemodynamically most economical or appropriate course of action. This is a question hitherto only answered by the 'maximisation concept' in volume resuscitation based on the Starling cardiac function 


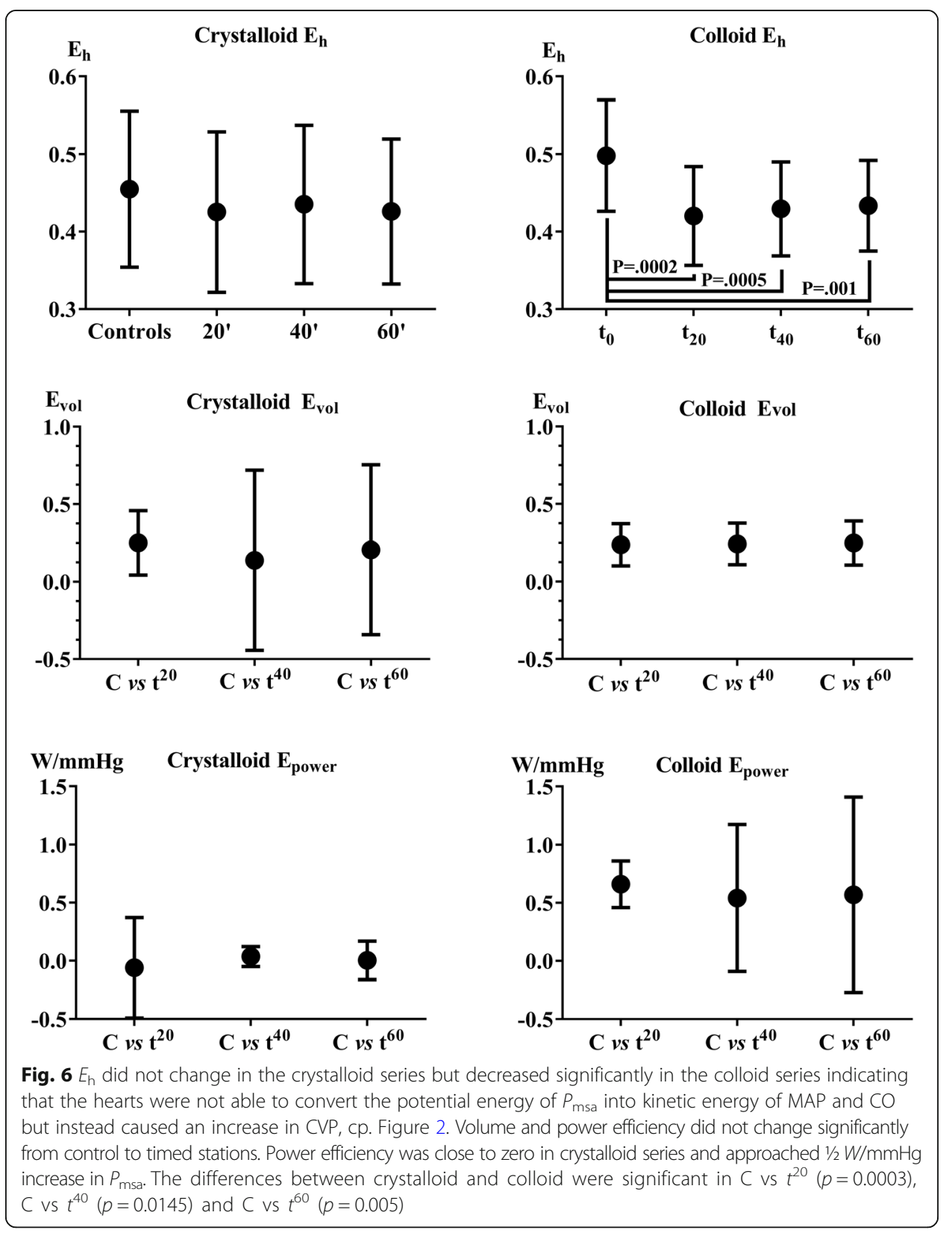

curve, and it is worthwhile to contemplate the meaning of 'economical' in this context. Studies from Starling [23] onwards relating the pressure-volume area (PVA) to oxygen consumption $\left(\mathrm{VO}_{2}\right)$ arrive at a linear relationship in denervated conscious dogs. A higher preload in accordance with the Starling function curve leads to a higher $\mathrm{CO}$ and conceptually to a higher PVA and proportionally higher $\mathrm{VO}_{2}$. This linearity is valid at varied contractility (dobutamine infusion) in combination with variations in preload. [24] Thus, we cannot argue the 'economy' point from oxygen consumption.

Contemplate instead the aim of GDT: to guarantee oxygen delivery and adequate perfusion pressure for vital organs. The question of oxygen demand is rarely contemplated; rather it is supplanted with a dogma of optimisation/maximisation of flow. The dogma dictates that fluid is the sole means to optimise flow. A flow, which in the intact organism, 


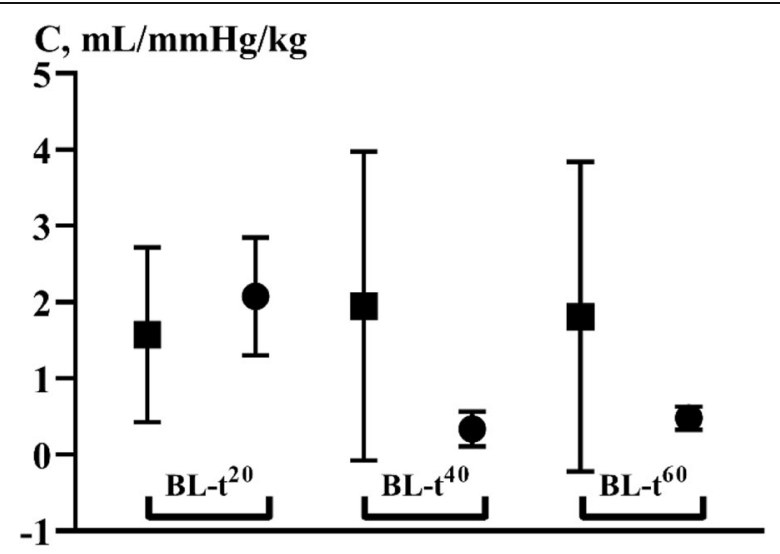

Compliance based on retained volume

Fig. 7 The compliances calculated from change in $P_{\text {msa }}$ from baseline to $t^{20}, t^{40}$ and $t^{60}$, and volume infused differed significantly between crystalloid and colloid ( $p=<0.0001,0.0013$ and 0.0034$)$ at identical time points. Crystalloid, full square; colloid, full circle

is autoregulated according to $\mathrm{VO}_{2}$. Bundgaard-Nielsen $[25,26]$ fortuitously demonstrated this by volume loading awake, normal, unmedicated subjects with colloid. No increases in $\mathrm{CO}$ were observed using CardioQ. In another study, the author resuscitated anaesthetized patients with $200 \mathrm{~mL}$ colloid boli if SV increased >10\% from prior bolus. The volume needed was interpreted as 'functional intravascular volume deficit' and amounted to 200 to $600 \mathrm{~mL}$. It is tempting to infer that in the first case, the intact organism redistributed the volume to the unstressed volume as the subjects were in no need of a higher $\mathrm{CO}$ or $\mathrm{DO}_{2}$. The splanchnic circulation has the ability to store added fluid as unstressed volume by increasing vascular capacitance dictated by the intact autoregulation of $\mathrm{CO}$ to $\mathrm{VO}_{2}$. In the second case, it is most probable that sympathetic reflexes and autoregulatory mechanisms have been attenuated by anaesthesia and that sympathicolysis has contributed to greater venous capacitance.

Circumstantial evidence can be drawn from passive leg raising (PLR). In the intact, unmedicated organism, PLR can be seen to increase CO in the short term $(2-5 \mathrm{~min})$. One textbook recommends that the assessment of volume responsiveness by PLR must be done within the first minute $[27,28]$ as 'the maximal hemodynamic effects of PLR occur within the first minute of leg elevation.' At this point, autoregulation kicks in and lowers CO, probably by the combined effect of redistributing volume to the unstressed compartment and lowering heart rate as a baroreceptor response [29]. The method of volume optimisation based on 10\% increase in SV may even miss its own intention. The volume bolus must add pressure to the stressed volume and the pressure gradient for venous return in sufficient measure to affect an increase in CO of the stipulated 10\% (o: change the loading condition). It may further be hampered by the confounding response to haemodilution in terms of reflex increase in CO. [30,31] The pressure addition is dictated by fluid retention, vascular compliance and the distribution of blood volume between systemic and splanchnic vascular beds. The increase in $P_{\text {msa }}$ may be zero if added volume is deposited in increased venous capacitance.

'Economy' takes on a new meaning when addressing the efficiency variables. Heart efficiency, compliance, fluid state and resistance are never addressed by the adherents to the Starling-based maximisation concept. It has to be admitted that hitherto, there 
has been no discussion pertaining to these in Guytonian-oriented literature, there is absolutely no discussion as to branching values suggesting choice of intervention in terms of fluid, vaso- and/or cardioactive interventions. In the present analysis, evidently $E_{\mathrm{h}}$ significantly decreased as a result of the infused volume. $E_{\mathrm{h}}$ is a static measure, and there is no guideline as to which value should preclude the continued use of fluids and invite the use of inotropes or vasopressors. In the Navigator Clinical Decision Support System, an $E_{\mathrm{h}}<0.3$ is suggestive of the use of inotropes rather than fluids. In a clinical study relating (binary) volume responsiveness to (continuous) volume efficiency, the mean value of $E_{\mathrm{vol}}$ was 0.35 in responders and 0.1 in non-responders. [32] The $\Delta \mathrm{CO}$ of $15-25 \%$ in the present study is obviously at the expense of a disproportionate increase in CVP signalling the increased distension of the right ventricle and the relative inability of the heart to eject the added volume. An increased CVP per se ( 0 : without a corresponding increase in $P_{\mathrm{ms}}$ ), furthermore, is associated with decreased drainage from venous beds, irrespective of arterial perfusion pressure. This creates a problem with increased bleeding during surgery severing venous plexuses. In the intensive care unit, an elevated CVP inhibits the drainage of kidney, intestines and lungs with known detrimental effects of kidney failure, impaired peristalsis and oedema. [33]

The dynamic counterpart to $E_{\mathrm{h}}$ is $E_{\mathrm{vol}}$. As in the case of $E_{\mathrm{h}}$, we have no safe guidance as to branching value in the decision pathway but a value in the interval 0.5 to 1 may be a suggestion.

We introduce the calculation of power efficiency, $E_{\text {power }}$ showing the same pattern as $E_{\mathrm{h}}$ and $E_{\mathrm{vol}}$ : slightly declining and with great variance in the crystalloid group and rather stable with low variance in the colloid group. $E_{\text {power }}$ is derived from cardiovascular power as $\mathrm{CO} \times$ MAP. This has been shown to correlate highly with mortality in the ICU. [34]

Intentionally, we have not made comparisons with prevailing methods of volume responsiveness (positive pressure ventilation induced changes in venous return reflected in left-sided variables as pulse pressure or stroke volume variation) as the physiological foundation of these is too inconsistent and garnered in caveats. [35, 36] The trend is toward abandoning them. [27]

\section{Conclusion}

In conclusion, we have demonstrated the haemodynamic effects of crystalloid and colloid resuscitation in post-CABG patients. The primary variables MAP, RAP and CO beguile the clinician-in other circumstances-to assess that volume resuscitation was successful while the efficiency variables demonstrate that the added volume comes with the cost of actually straining the organism with a disproportionate increase in CVP. It is furthermore demonstrated that crystalloid volume has a highly variable and unpredictable effect dependent on its degree of fluid retention.

\section{Appendix}

$$
\text { Power }=\mathrm{CO} \times(\mathrm{MAP}-\mathrm{RAP}) \times 0.0022, \mathrm{~W}
$$


Volume efficiency, $E_{\mathrm{vol}}$, may appropriately answer the question of whether fluid, vasopressor or inotropic therapy is more conducive to the target of increasing $\mathrm{CO}$ and by implication $\mathrm{DO}_{2}$.

$$
E_{\mathrm{vol}}=\frac{\Delta\left(P_{\mathrm{msa}}-\mathrm{RAP}\right)}{\Delta P_{\mathrm{msa}}},[0 ; 1]
$$

Additionally, it may be of interest to characterise power efficiency, $E_{\text {power }}$ in terms of the ratio between the change in power $(\mathrm{MAP} \times \mathrm{CO})$ and the change in $P_{\text {msa }}$.

$$
E_{\text {power }}=\frac{\Delta((\mathrm{MAP}-\mathrm{RAP}) \times \mathrm{CO}) \times 0.0022}{\Delta P_{\mathrm{msa}}}, \mathrm{W} / \mathrm{mmHg},[0 ; 1]
$$

\begin{abstract}
Abbreviations
BV: Blood volume; C: Compliance; CABG: Coronary artery bypass grafting; CDSS: Clinical decision support system; CVP: Central venous pressure; $\mathrm{DO}_{2}$ : Oxygen delivery; $\mathrm{E}_{\mathrm{h}}$ : Heart efficiency; $\mathrm{E}_{\mathrm{powe}}$ : Power efficiency; $\mathrm{E}_{\mathrm{vol}}$ : Volume efficiency; FR: Fluid retention; GDT: Goal directed therapy; Hb: Haemoglobin; Hct: Haematocrit; ICU: Intensive care unit; MAP: Mean arterial pressure; PEEP: Positive end expiratory pressure; PLR: Passive leg raising; $\mathrm{P}_{\mathrm{ms}}$ : Mean systemic filling pressure; $\mathrm{P}_{\text {msa: }}$ : Mean systemic filling pressure analogue; PVA: Pressure-volume area; RAP: Right atrial pressure; $\mathrm{S}_{\mathrm{a}} \mathrm{O}_{2}$ : Arterial oxygen saturation; SV: Stroke volume; TDCO: Transcardiac thermodilution cardiac output; $\mathrm{VO}_{2}$ : Oxygen consumption
\end{abstract}

\title{
Acknowledgements
}

Professor emeritus Geoffrey Parkin, Monash University, Melbourne, Australia is warmly acknowledged for commenting, correcting and improving the finer details of the mathematical formulation of the Guytonian approach to cardiovascular regulation.

\section{Ethics Approval and consent to participate}

The underlying study was approved by the Regional Ethical Review Board in Gothenburg, registration no. 158-09 and registered in ClinicalTrials.gov, identifier: NCT01729364.

No approval was sought for the re-analyses of data as contained in present manuscript.

\section{Funding}

The study received no funding.

Availability of data and materials

Please contact author for data requests.

\section{Authors' contributions}

SS performed the reanalyses of primary data, consulted JS and PM who checked and complemented the statistics and results. All authors read and approved the final manuscript and eventually the submission for publication.

\section{Consent for publication}

Not applicable.

\section{Competing interests}

The authors declare that they have no financial or non-financial competing interests in terms of reimbursements, fees, funding, or salary, stocks or shares, holding, or currently applying for, patents; political, personal, religious, ideological, academic, and intellectual competing interests.

\section{Publisher's Note}

Springer Nature remains neutral with regard to jurisdictional claims in published maps and institutional affiliations.

\section{Author details}

${ }^{1}$ Centre of Elective Surgery, Department of Anaesthesia and Intensive Care, Silkeborg Regional Hospital, Silkeborg, Denmark. ${ }^{2}$ Swedish Armed Forces, Stockholm, Sweden. ${ }^{3}$ Department of Anaesthesiology and Intensive Care Medicine, Institute of Clinical Sciences at the Sahlgrenska Academy, University of Gothenburg, Sahlgrenska University Hospital Östra, Gothenburg, Sweden.

Received: 3 September 2018 Accepted: 29 January 2019

Published online: 04 March 2019

\section{References}

1. Skytte Larsson J, Bragadottir G, Krumbholz V, Redfors B, Sellgren J, Ricksten SE (2015) Effects of acute plasma volume expansion on renal perfusion, filtration, and oxygenation after cardiac surgery: a randomized study on crystalloid vs colloid. Br J Anaesth 115:736-742

2. Nadler SB, Hidalgo JH, Bloch T (1962) Prediction of blood volume in normal human adults. Surgery 51:224-232 
3. Weber E-H, (1850) Ueber die Anwendung der Wellenlehre vom Kreislaufe des Blutes und insbesondere auf die Pulslehre Berichte über die Verhandlungen der Königlichen Sächsischen Gesellschaft der Wissenschaften zu Leipzig Mathematisch-Physische Classe 2: 164-204

4. Starling EH (1897) Some points in the pathology of heart disease. Lecture II. Lancet March 6:652-655

5. Guyton AC (1955) Determination of cardiac output by equating venous return curves with cardiac response curves. Physiol Rev 35:123-129

6. Guyton AC, Armstrong GG, Chipley PL (1956) Pressure-volume curves of the arterial and venous systems in live dogs. Am J Phys 184:253-258

7. Guyton AC, Lindsey AW, Abernathy B, Richardson T (1957) Venous return at various right atrial pressures and the normal venous return curve. Am J Phys 189:609-615

8. Guyton AC, Lindsey AW, Kaufmann BN (1955) Effect of mean circulatory filling pressure and other peripheral circulatory factors on cardiac output. Am J Phys 180:463-468

9. Guyton AC, Polizo D, Armstrong GG (1954) Mean circulatory filling pressure measured immediately after cessation of heart pumping. Am J Phys 179:261-267

10. Guyton AC, Jones CE, Coleman TG (1973) Cardiac output and its regulation. Saunders, Philadelphia

11. Maas JJ, Geerts BF, van den Berg PC, Pinsky MR, Jansen JR (2009) Assessment of venous return curve and mean systemic filling pressure in postoperative cardiac surgery patients. Crit Care Med 37:912-918

12. Maas JJ, Pinsky MR, Aarts LP, Jansen JR (2012) Bedside assessment of total systemic vascular compliance, stressed volume, and cardiac function curves in intensive care unit patients. Anesth Analg 115:880-887

13. Maas JJ, Pinsky MR, de Wilde RB, de Jonge E, Jansen JR (2013) Cardiac output response to norepinephrine in postoperative cardiac surgery patients: interpretation with venous return and cardiac function curves. Crit Care Med 41:143-150

14. Maas JJ, Pinsky MR, Geerts BF, de Wilde RB, Jansen JR (2012) Estimation of mean systemic filling pressure in postoperative cardiac surgery patients with three methods. Intensive Care Med 38:1452-1460

15. Jansen JR, Maas JJ, Pinsky MR (2010) Bedside assessment of mean systemic filling pressure. Curr Opin Crit Care 16:231-236

16. van den Berg PC, Jansen JR, Pinsky MR (2002) Effect of positive pressure on venous return in volume-loaded cardiac surgical patients. J Appl Physiol 92:1223-1231

17. Versprille A, Jansen JR (1985) Mean systemic filling pressure as a characteristic pressure for venous return. Pflugers Archiv : European journal of physiology 405:226-233

18. Parkin WG (1999) Volume state control-a new approach. Critical care and resuscitation : journal of the Australasian Academy of Critical Care Medicine 1:311-321

19. Parkin WG, Leaning MS (2008) Therapeutic control of the circulation. J Clin Monit Comput 22:391-400

20. Parkin WG, Wright CA (1991) Three dimensional closed loop control of the human circulation. Int J Clin Monit Comput 8:35-42

21. Parkin G, Wright C, Bellomo R, Boyce N (1994) Use of a mean systemic filling pressure analogue during the closed-loop control of fluid replacement in continuous hemodiafiltration. J Crit Care 9:124-133

22. Marik PE (2014) latrogenic salt water drowning and the hazards of a high central venous pressure. Ann Intensive Care 4:21

23. Starling $E H$, Visscher MB (1927) The regulation of the energy output of the heart. J Physiol 62:243-261

24. Nozawa T, Cheng CP, Noda T, Little WC (1994) Relation between left ventricular oxygen consumption and pressure-volume area in conscious dogs. Circulation 89:810-817

25. Bundgaard-Nielsen M, Jorgensen CC, Kehlet H, Secher NH (2010) Normovolemia defined according to cardiac stroke volume in healthy supine humans. Clin Physiol Funct Imaging 30:318-322

26. Bundgaard-Nielsen M, Jorgensen CC, Secher NH, Kehlet H (2010) Functional intravascular volume deficit in patients before surgery. Acta Anaesthesiol Scand 54:464-469

27. Marik PE (2015) Evidence-based critical care. Springer, Cham

28. Monnet X, Rienzo M, Osman D, Anguel N, Richard C, Pinsky MR, Teboul JL (2006) Passive leg raising predicts fluid responsiveness in the critically ill. Crit Care Med 34:1402-1407

29. Nemoto, K., T. Kaiho, S. Ito, K. Yoshioka, and A. Maki (2016) Effects of passive leg raising on cardiovascular functions as analyzed by fingertip pulse pressure profiles. Biomed Res Clin Prac 1(3):76-81. https://doi.org/10.15761/BRCP.1000115

30. K M (1972) Circulatory significance of hemodilution: reological changes and limitations. In: Harders H (ed) Advances in microcirculation. S. Karger. Basel, New York, pp 1-77

31. Guyton AC, Richardson TQ (1961) Effect of hematocrit on venous return. Circ Res 9:157-164

32. Gupta K, Sondergaard S, Parkin G, Leaning M, Aneman A (2015) Applying mean systemic filling pressure to assess the response to fluid boluses in cardiac post-surgical patients. Intensive Care Med 41:265-272

33. Legrand M, Dupuis C, Simon C, Gayat E, Mateo J, Lukaszewicz AC, Payen D (2013) Association between systemic hemodynamics and septic acute kidney injury in critically ill patients: a retrospective observational study. Crit Care 17:R278

34. Mendoza DD, Cooper HA, Panza JA (2007) Cardiac power output predicts mortality across a broad spectrum of patients with acute cardiac disease. Am Heart J 153:366-370

35. Mahjoub Y, Lejeune V, Muller L, Perbet S, Zieleskiewicz L, Bart F, Veber B, Paugam-Burtz C, Jaber S, Ayham A, Zogheib E, Lasocki S, Vieillard-Baron A, Quintard H, Joannes-Boyau O, Plantefeve G, Montravers P, Duperret S, Lakhdari M, Ammenouche N, Lorne E, Slama M, Dupont H (2014) Evaluation of pulse pressure variation validity criteria in critically ill patients: a prospective observational multicentre point-prevalence study. Br J Anaesth 112:681-685

36. Sondergaard S (2013) Pavane for a pulse pressure variation defunct. Crit Care 17:327 